\title{
A simple filter model to guide the allocation of healthcare resources for improving the treatment of depression among cancer patients
}

Robert W. Sanson-Fisher ${ }^{1,2,3}$, Natasha E. Noble ${ }^{1,2,3^{*}}$, Andrew M. Searles ${ }^{2,3}$, Simon Deeming ${ }^{3}$, Rochelle E. Smits ${ }^{1,2,3}$, Christopher J. Oldmeadow $w^{2,3,4}$ and Jamie Bryant ${ }^{1,2,3}$

\begin{abstract}
Background: Depression is highly prevalent yet often poorly detected and treated among cancer patients. In light of the move towards evidence-based healthcare policy, we have developed a simple tool that can assist policy makers, organisations and researchers to logically think through the steps involved in improving patient outcomes, and to help guide decisions about where to allocate resources.

Methods: The model assumes that a series of filters operate to determine outcomes and cost-effectiveness associated with depression care for cancer patients, including: detection of depression, provider response to detection, patient acceptance of treatment, and effectiveness of treatment provided. To illustrate the utility of the model, hypothetical data for baseline and four scenarios in which filter outcomes were improved by 15\% were entered into the model.

Results: The model provides outcomes including: number of people successfully treated, total costs per scenario, and the incremental cost-effectiveness ratio per scenario compared to baseline. The hypothetical data entered into the model illustrate the relative effectiveness (in terms of the number of additional incremental successes) and relative cost-effectiveness (in terms of cost per successful outcome and total cost) of making changes at each step or filter.

Conclusions: The model provides a readily accessible tool to assist decision makers to think through the steps involved in improving depression outcomes for cancer patents. It provides transparent guidance about how to best allocate resources, and highlights areas where more reliable data are needed. The filter model presents an opportunity to improve on current practice by ensuring that a logical approach, which takes into account the available evidence, is applied to decision making.
\end{abstract}

Keywords: Depression, Cancer, Oncology, Modelling, Costs, Patient outcomes, Decision aid, Filter

\section{Background}

How can the treatment of depression among cancer patients be improved?

Depression is a significant problem for cancer patients. The rate of occurrence of major depression among cancer patients is approximately two to four times that of the general population [1]. Depressive symptoms and distress

\footnotetext{
* Correspondence: Natasha.Noble@newcastle.edu.au

${ }^{1}$ Priority Research Centre for Health Behaviour, University of Newcastle, Callaghan, NSW, Australia

${ }^{2}$ School of Medicine and Public Health, Faculty of Health and Medicine, University of Newcastle, Callaghan, NSW, Australia

Full list of author information is available at the end of the article
}

are associated with negative outcomes and disability, including more rapidly progressing cancer symptoms, more metastasis, pain, and poorer quality of life, compared with non-depressed cancer patients [2,3]. Yet research indicates that depression and distress are underrecognised and under-treated among cancer patients [4-6]. While routine screening for distress is mandated as standard practice in cancer treatment settings $[7,8]$, there is only sparse evidence that such interventions are of benefit to patients [9]. Why is this so? Clearly, screening needs to be linked to other changes in the system of care to increase the provision of effective treatment $[1,10,11]$. 
Other factors which affect the provision of treatment include whether providers refer or offer treatment services to depressed patients, and whether patients accept an offer of treatment [12, 13]. If depression outcomes for cancer patients are to be improved, the range of relevant steps and influences on outcomes need to be adequately considered.

\section{How should decisions about allocating resources to improve patient outcomes be made?}

Following the move towards evidence-based medicine, evidence-based policy is also being encouraged in all areas of public service, including health care [14]. However, reviews of public health sector decisions suggest that research currently has little direct influence on decision making $[14,15]$. Policymakers tend to rely on other types of evidence, such as personal experience, or the opinions of eminent colleagues, rather than research findings [14].

A range of methods are available to assist policy makers and organisations to make evidence-based decisions about the allocation of healthcare resources. For example, decision analytic modelling is a systematic process which utilises the best available information to inform a decision when faced with various sources of uncertainty $[16,17]$. Other decision making tools include techniques such as cost-effectiveness and cost benefit analysis. However, such techniques are often highly complex and require advanced skills to implement, as well as a significant investment of time and resources [18, 19]. Given the need to move towards evidence-based healthcare policy, and the limitations of utilising the currently available decision tools, there is a need for a simple tool that can assist policy makers, organisations and researchers to logically think through the steps involved in improving patient outcomes, and to make the best use of the available data. Such a tool will also serve to highlight where additional data are needed to support evidence-based decision making.

\section{A simple "filter model" to guide decisions about the investment of resources to improve the treatment of depression among cancer patients}

In light of the constraints mentioned above, we have developed a simple 'filter model' to assist decision and policy makers think through some of the key steps that influence patient outcomes in depression care in cancer. The model will help guide decisions about where to best allocate resources to improve outcomes based on available evidence. The filter model combines epidemiological, statistical and economic approaches to guide policy decision making, and aims to increase the transparency of the decision making process by identifying the factors that contribute to the decision. The filter model forms a checklist of important considerations along the path of policy development, and serves to highlight those steps or aspects of care where research evidence is lacking.

In this paper we describe the application of the filter model to the allocation of resources in the treatment of depression for cancer patients. The model assumes that a series of filters operate to determine outcomes and cost-effectiveness associated with depression care. The model allows for data and costs to be entered at each step, and provides a range of metrics which allow outcome scenarios to be compared to a baseline. Although the model is set up to explore the treatment of depression in cancer patients, it can also potentially be applied to similar policy and healthcare resource allocation decisions, such as the treatment of obesity, or provision of smoking cessation strategies in General Practice.

\section{Aims}

The aims of this paper were to: a) illustrate some of the key steps which operate to determine depression outcomes for cancer patients; b) provide decision and policy makers with a simple tool for guiding decisions about how to allocate resources to improve patient outcomes; and c) highlight areas of the literature where more research about depression care for cancer patients is needed. The filter model is a currently a theoretical tool which can be empirically tested to explore its utility and reliability.

\section{Method}

\section{Definition of the model filters}

Four key filters were included in the model as outlined in Fig. 1. These filters included: a) Detection of depression; b) Provider response to detection; c) Patient acceptance of treatment for depression; and d) Effectiveness of the treatment offered for depression. While there are a range of additional filters which might also influence depression outcomes among cancer patients, these four were drawn from the literature as representing those factors likely to have the greatest influence on patient outcomes.

Numerous authors note the poor levels of detection of depression by providers $[4-6,10,12]$, and the role that screening can play in improving detection [12, 20]. Estimates of the correct rate of detection of depression among cancer patients by clinician judgement alone range from 5 to $37 \%$ [4, 21, 22], while the use of screening tools has been shown to improve the recognition of depression [23]. Similarly, a large body of research has focussed on the effectiveness of treatments for depression, including psychological and pharmacological approaches [24, 25], and more recently, collaborative care models [26]. Collaborative care approaches have demonstrated significant treatment success [27-29]. 


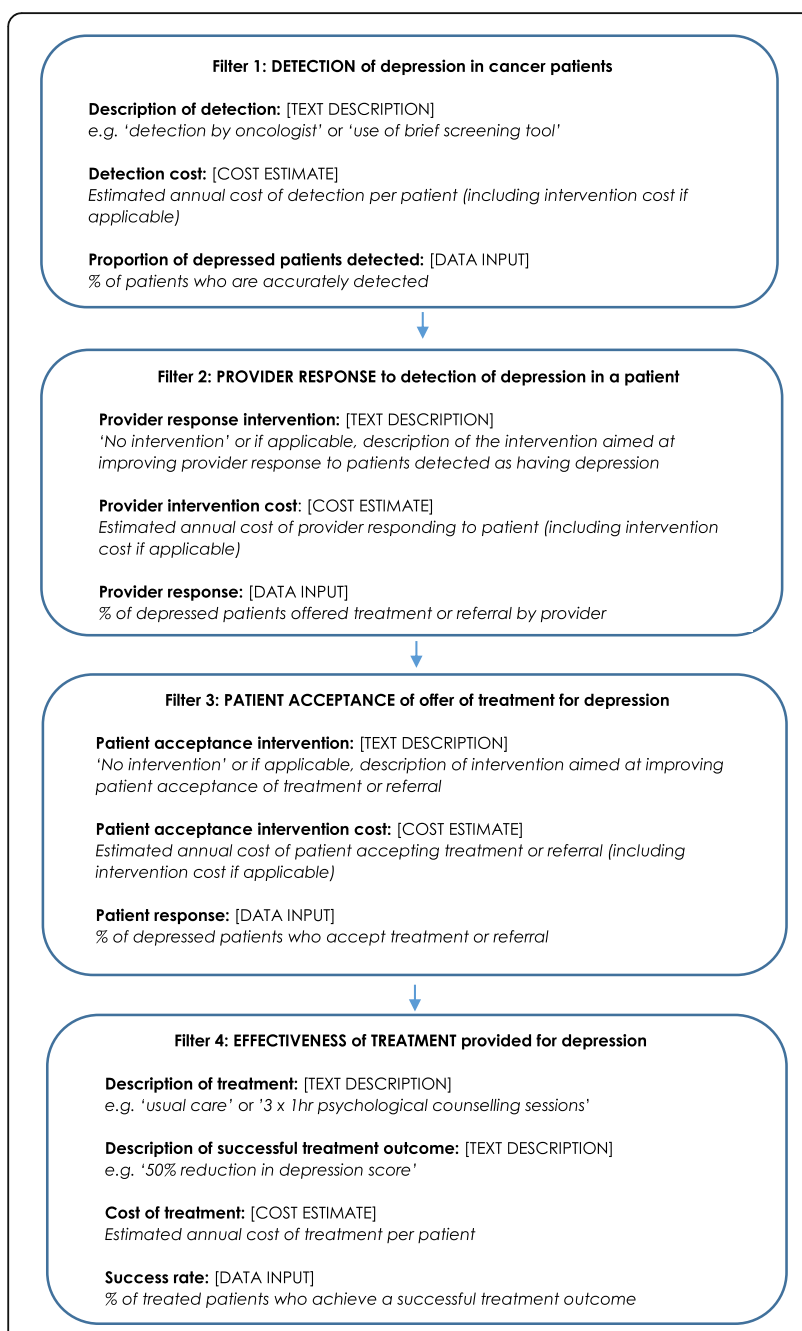

Fig. 1 Key filters included in the filter model for allocation of healthcare resources in improving treatment of depression in cancer

However, the receipt of care following detection is a key limiting factor $[7,11]$. Screening for depression is unlikely to benefit patients unless it is accompanied by strategies such as providing clinicians with an interpretation of scores, mandating follow-up, and training or other clinician support [11]. In a review of barriers to the treatment of depression in cancer care, Greenberg 2004 reported the lack of provider referral and lack of patient awareness of treatment services as major barriers to the receipt of care [12]. Mitchell 2013 also reported patient lack of acceptance of treatment offered for depression as a key barrier to the receipt of care [13]. This is illustrated by reports that suggest fewer than $10 \%$ of cancer patients with significant distress are referred for psychosocial care [30]. Other authors report that only approximately one-quarter of cancer patients with depression receive treatment [31, 32]. Similarly, across several studies, only $36 \%$ of distressed cancer patients expressed a desire for help [33], less than a quarter of lung cancer patients indicated an interest in receiving help for their distress [34], and less than a third of cancer outpatients accepted an offer of help for distress [35]. Some of the reasons patients may decline treatment include a preference to self-manage, or a perception that symptoms are not severe enough to require treatment [35].

\section{Model design}

The filter model operates within an excel spreadsheet and uses pre-defined cell algorithms. Text descriptions and numerical data, including costs, are entered into the model for a number of background parameters (including defining the nature and size of the total population and target group) and parameters reflecting attributes of each of the four model filters:

1) Detection of depression: includes a text description of how detection is undertaken, the cost associated, and the rate of correct identification of cases of depression;

2) Provider response to detection: the proportion of cancer patients who are offered treatment or a referral for treatment in response to having been identified as having depression, and associated cost;

3) Patient acceptance of treatment: the proportion of cancer patients that would be willing to accept assistance if offered some kind of treatment for depression, and associated cost;

4) Treatment effectiveness:. The proportion of patients that are successfully treated for depression (out of those that accepted treatment), and associated cost.

The model allows the user to create multiple hypothetical intervention and usual care scenarios to compare outcomes under a range of assumptions about the input data. For example, the user could model the outcomes associated with adopting a range of different approaches to the detection of depression, such as ultra-short, short, and interview style screening tools, including the anticipated cost of each approach.

Given the input data representing the background and filter model parameters, the following outcomes are estimated for each of the scenarios of interest:

1) Cost per patient: Aggregate cost of the treatment pathway for all patients, divided by the number of patients who participate in treatment;

2) Cost per successful outcome: Aggregate cost of the treatment pathway for all patients, divided by the number of patients who are successfully treated for depression;

3) Incremental cost compared to baseline: Additional aggregate cost of the treatment pathway for all 
patients under each scenario compared to the baseline scenario;

4) Incremental number of successes compared to baseline: The number of additional patients who achieve a successful outcome under each scenario compared to the baseline scenario;

5) Incremental cost-effectiveness ratio (ICER): Incremental cost compared to baseline (c) divided by the incremental number of successes compared to baseline (d). The ICER is the ratio of the change in cost to the change in effectiveness of each scenario compared to the baseline. It provides an estimate of the additional cost per successful outcome under each scenario compared to baseline;

a) Policy advice: The model indicates whether each scenario is more or less expensive (incremental cost) and more or less effective (incremental number of successes) compared to the baseline scenario.

\section{Procedure}

In order to illustrate use of the model for highlighting key steps which contribute to depression outcomes for cancer patients, and as a decision tool for how resources might be allocated to improve patient outcomes, hypothetical data for baseline and four different scenarios were entered into the model. The four scenarios modelled a hypothetical 15\% improvement from baseline care in each of the 4 filters: detection of depression (from 20\% at baseline to $35 \%$ in scenario 1), provider response to detection of depression (from $70 \%$ at baseline to $85 \%$ in scenario 2), patient acceptance of an offer of treatment for depression (from $30 \%$ at baseline to $45 \%$ in scenario 3 ), and the effectiveness of treatment offered for depression (from 30\% at baseline to $45 \%$ in scenario 4). Arbitrary costs associated with baseline care and with achieving these improvements were also entered into the model.

\section{Results}

Input data used and the results of the modelling of the hypothetical scenarios are presented in Table 1.

Under the assumptions made for the baseline and four scenarios:

- Compared to baseline, scenario 1 ( $\uparrow$ detection) produced 14 additional incremental successes, scenarios 3 ( $\uparrow$ patient acceptance of treatment) and 4 ( $\uparrow$ treatment effectiveness) produced 9 additional successes, and scenario 2 ( $\uparrow$ provider response) produced 4 additional successfully treated patients;

- Compared to baseline, scenario 3 ( $\uparrow$ patient acceptance) had the lowest cost per additional successful outcome of the four scenarios, and therefore the lowest ICER; Scenario 3 was the most cost-effective of the three non-baseline scenarios;

- Compared to baseline, scenario 4 ( $\uparrow$ treatment effectiveness) had the highest cost per additional successful outcome of the three non-baseline scenarios, and therefore the highest ICER; Scenario 4 was the least cost-effective option of the three non-baseline scenarios;

- Scenarios $2(\uparrow$ provider response) and $1(\uparrow$ detection) had intermediary costs per additional successful outcome and ICER values, compared to baseline.

The model also provides decision makers with information on the total budgetary change required to implement proposed changes to the treatment pathway. Based on the hypothetical data, Scenario 3 ( $\uparrow$ patient acceptance) would require the allocation of an additional $\$ 4725$ above baseline to deliver an additional 9 successes. Scenario 4 ( $\uparrow$ treatment effectiveness) would require an additional $\$ 12,600$ to deliver the same number of additional successes. The greatest number of additional successes $(n=14)$ could be achieved under scenario 1 ( $\uparrow$ detection), for a total additional cost of $\$ 13,350$. The least number of additional successes were achieved $(n=4)$ at a total additional cost of $\$ 2850$ under scenario 2 ( $\uparrow$ provider response).

\section{Discussion}

Ideally all cancer patients with depression should be identified and treated. However, given increasingly limited healthcare budgets, this simple filter tool can assist decision makers to make transparent decisions about the allocation of scarce resources to best improve depression outcomes in cancer settings. While the simplicity of the tool necessitates some limitations, it should help decision makers to identify and consider relevant parameters that may influence an investment decision. It also helps identify the data that needs to be sourced to help inform decisions, and provides a prompt to utilise the existing research evidence, where available. Use of the model therefore represents a potential improvement on the current situation where there is little or no consideration given to the available evidence.

The filter model is a tool for exploring the impact of changes to the depression treatment pathway on patient outcomes and clinic costs. The results can be used to inform decision makers about the possible returns from investments in a given field. This information provides additional clarity about where resources can or should be allocated for best value for money. In the setting illustrated, the filter model describes, and makes transparent, a logical decision making pathway for considering a 
Table 1 Model parameters and output under hypothetical usual care and four scenarios of improvement above baseline

\begin{tabular}{|c|c|c|c|c|c|}
\hline Model Parameters & Baseline & $\begin{array}{l}\text { Scenario 1: Increase } \\
\text { detection }\end{array}$ & $\begin{array}{l}\text { Scenario 2: Increase } \\
\text { provider response }\end{array}$ & $\begin{array}{l}\text { Scenario 3: Increase } \\
\text { patient acceptance }\end{array}$ & $\begin{array}{l}\text { Scenario 4: Increase } \\
\text { treatment effectiveness }\end{array}$ \\
\hline \multicolumn{6}{|l|}{ Population } \\
\hline $\begin{array}{l}\text { Arbitrary population } \\
\text { of cancer patients }\end{array}$ & 10,000 & 10,000 & 10,000 & 10,000 & 10,000 \\
\hline \multicolumn{6}{|l|}{ Target group } \\
\hline $\begin{array}{l}\text { Cancer patients with } \\
\text { depression }\end{array}$ & $15 \% n=55,500$ & $15 \% n=55,500$ & $15 \% n=55,500$ & $15 \% n=55,500$ & $15 \% n=55,500$ \\
\hline \multicolumn{6}{|l|}{ Filter 1: detection } \\
\hline Detection (description) & $\begin{array}{l}\text { Clinician } \\
\text { judgement }\end{array}$ & $\begin{array}{l}\text { Computerised short } \\
\text { screening tool }\end{array}$ & Clinician judgement & Clinician judgement & Clinician judgement \\
\hline$\%$ and no. detected & $20 \% n=300$ & $35 \% n=525$ & $20 \% n=300$ & $20 \% n=300$ & $20 \% n=300$ \\
\hline $\begin{array}{l}\text { Cost for detection } \\
\text { (per person) }\end{array}$ & $\$ 5$ & $\$ 10.00$ & $\$ 5$ & $\$ 5$ & $\$ 5$ \\
\hline Total cost for filter 1 & $\$ 7500$ & $\$ 15,000$ & $\$ 7500$ & $\$ 7500$ & $\$ 7500$ \\
\hline \multicolumn{6}{|l|}{ Filter 2: Provider response } \\
\hline $\begin{array}{l}\text { Provider response } \\
\text { (description) }\end{array}$ & $\begin{array}{l}\text { Clinician } \\
\text { judgement }\end{array}$ & Clinician judgement & $\begin{array}{l}\text { Provision of patient distress } \\
\text { screening scores and } \\
\text { recommendation to clinician }\end{array}$ & Clinician judgement & Clinician judgement \\
\hline$\%$ and no. offered treatment & $70 \% n=210$ & $70 \% n=368$ & $85 \% n=255$ & $70 \% n=210$ & $70 \% n=210$ \\
\hline Cost for provider (per person) & $\$ 5$ & $\$ 5$ & $\$ 10$ & $\$ 5$ & $\$ 5$ \\
\hline Total cost for filter 2 & $\$ 1500$ & $\$ 2625$ & $\$ 3000$ & $\$ 1500$ & $\$ 1500$ \\
\hline \multicolumn{6}{|l|}{ Filter 3: Patient acceptance } \\
\hline $\begin{array}{l}\text { Patient acceptance } \\
\text { (description) }\end{array}$ & $\begin{array}{l}\text { Patient } \\
\text { judgement }\end{array}$ & Patient judgement & Patient judgement & $\begin{array}{l}\text { Distress scores \& } \\
\text { recommendation } \\
\text { provided to patient }\end{array}$ & Patient judgement \\
\hline$\%$ and no. accept treatment & $30 \% n=63$ & $30 \% n=110$ & $30 \% n=77$ & $45 \% n=95$ & $30 \% n=63$ \\
\hline $\begin{array}{l}\text { Cost for acceptance } \\
\text { (per person) }\end{array}$ & $\$ 0$ & $\$ 0$ & $\$ 0$ & $\$ 7.50$ & $\$ 0$ \\
\hline Total cost for filter 3 & $\$ 0$ & $\$ 0$ & $\$ 0$ & $\$ 1575$ & $\$ 0$ \\
\hline \multicolumn{6}{|l|}{ Filter 4: Treatment efficacy } \\
\hline Treatment (description) & $\begin{array}{l}\text { Referral to } \\
\text { primary care }\end{array}$ & Referral to primary care & Referral to primary care & Referral to primary care & Collaborative care model \\
\hline Treatment outcome & $\begin{array}{l}\text { No longer meets } \\
\text { diagnostic criteria for } \\
\text { depression }\end{array}$ & $\begin{array}{l}\text { No longer meets } \\
\text { diagnostic criteria for } \\
\text { depression }\end{array}$ & $\begin{array}{l}\text { No longer meets diagnostic } \\
\text { criteria for depression }\end{array}$ & $\begin{array}{l}\text { No longer meets } \\
\text { diagnostic criteria for } \\
\text { depression }\end{array}$ & $\begin{array}{l}\text { No longer meets diagnostic } \\
\text { criteria for depression }\end{array}$ \\
\hline$\%$ and no. treated successfully & $30 \% n=19$ & $30 \% n=33$ & $30 \% n=23$ & $30 \% n=28$ & $45 \% n=28$ \\
\hline $\begin{array}{l}\text { Cost for treatment } \\
\text { (per person) }\end{array}$ & $\$ 100$ & $\$ 100$ & $\$ 100$ & $\$ 100$ & $\$ 300$ \\
\hline Total cost for filter 4 & $\$ 6300$ & $\$ 11,025$ & $\$ 7650$ & $\$ 9450$ & $\$ 18,900$ \\
\hline \multicolumn{6}{|l|}{ Outcome metrics } \\
\hline Total cost & $\$ 15,300$ & $\$ 28,650$ & $\$ 18,110$ & $\$ 20,025$ & $\$ 27,900$ \\
\hline $\begin{array}{l}\text { Cost per patient receiving } \\
\text { care }\end{array}$ & $\$ 242.86$ & $\$ 260$ & $\$ 237$ & $\$ 212$ & $\$ 443$ \\
\hline Cost per successful outcome & $\$ 810$ & $\$ 866$ & $\$ 791$ & $\$ 706$ & $\$ 984$ \\
\hline $\begin{array}{l}\text { Incremental total cost } \\
\text { compared to baseline }\end{array}$ & $n / a$ & $\$ 13,350$ & $\$ 2850$ & $\$ 4725$ & $\$ 12,600$ \\
\hline $\begin{array}{l}\text { Incremental number of } \\
\text { patients successfully treated } \\
\text { compared to baseline }\end{array}$ & $n / a$ & 14 & 4 & 9 & 9 \\
\hline ICER & $\mathrm{n} / \mathrm{a}$ & $\$ 942$ & $\$ 704$ & $\$ 500$ & $\$ 1333$ \\
\hline Policy Advice & $n / a$ & $\begin{array}{l}\text { Compared to usual } \\
\text { care this scenario is } \\
\text { MORE EXPENSIVE } \\
\text { and has BETTER } \\
\text { EFFECTIVENESS }\end{array}$ & $\begin{array}{l}\text { Compared to usual care this } \\
\text { scenario is MORE EXPENSIVE } \\
\text { and has BETTER EFFECTIVENESS }\end{array}$ & $\begin{array}{l}\text { Compared to usual care } \\
\text { this scenario is MORE } \\
\text { EXPENSIVE and has } \\
\text { BETTER EFFECTIVENESS }\end{array}$ & $\begin{array}{l}\text { Compared to usual care } \\
\text { this scenario is MORE } \\
\text { EXPENSIVE and has } \\
\text { BETTER EFFECTIVENESS }\end{array}$ \\
\hline
\end{tabular}


range of interventions to improve outcomes for cancer patients experiencing depression. The transparency of this decision making pathway is, in itself, a process to engage and learn from stakeholders, so that these views can be incorporated into the decision making process.

Given the arbitrary nature of the data used to illustrate the filter model, the model results are not designed to make conclusions about which approach to improving treatment of depression is the best or most costeffective. The model is a theoretical tool which requires empirical testing, and may need to be refined as a result of such testing. Testing of the model across a range of contexts would be helpful, including for example: informing decisions where interventions are potentially very expensive, or where interventions are relatively affordable compared to the alternatives; informing where additional research is critical, such as a dominant parameter with little evidence; and/or educating decision makers regarding the implicit assumptions that are made within alternative options. Despite this, the filter model prompts the user to consider important parameters which impact on depression care, and provides a demonstration of how outcomes might change according to which aspects of depression care are altered. In the absence of readily available evidence, key model parameters can be elicited from content experts, and a range of plausible values can be explored to observe the variability in outcomes. Sensitivity analyses would be recommended where model parameters are varied to their plausible extremes if decisions were to be made from the results of the model.

\section{Who might use the simple filter model?}

The filter model has broad application for treatment centres, health departments, funding agencies and research groups. For treatment centres, the filter model is useful for examining the current care pathway and modelling the consequences of possible changes to this pathway. Under the hypothetical scenarios modelled in this paper, an intervention to increase patient acceptance of treatment by $15 \%$ led to the same number of incremental successes as increasing the effectiveness of treatment offered to patients, but at a fraction of the cost. The model can therefore be used to assist in conceptualising the consequences from changes to clinical systems. Through the process of logically considering the consequences from system changes or new interventions, it will be possible to assess the consequential downstream resourcing implications. For example, if the likely impact from a proposed intervention is an increase in the number of cases of depression that will be successfully detected, then the downstream impact would be expected to translate into a rise in the number of patients seeking treatment.
Decision makers can then examine existing capacity in the system to plan for the provision of sufficient resources.

For health departments, and within a given field, the model can be used to guide decision making about where to invest limited resources for the best value for money. For example, improving provider response to patients identified as depressed may be more costeffective than offering detected patients a more effective but more expensive treatment. Users can therefore select the intervention which provides the best outcome within a given budget.

For funding agencies and research groups, the filter model highlights aspects of depression treatment in cancer care where there is a lack of available evidence to help inform decision making. As a consequence, researchers and those who fund them can target their research efforts towards addressing these gaps in the evidence. For example, while considerable research effort has been expended on testing the effectiveness of screening for depression in cancer care [36, 37] and to some extent, for the treatment of depression for cancer patients $[38,39]$, there is a relative paucity of research examining other barriers to depression care among cancer patients [6], and in particular a lack of intervention research designed to overcome these barriers. There is also an almost complete absence of information available about the costs associated with implementing changes to the depression care pathway in cancer. Researchers and funding bodies urgently need to build in measures of effectiveness and cost effectiveness into future intervention studies.

\section{Advantages of the model}

This model provides a simple and accessible tool for guiding decisions about where to allocate resources to potentially improve depression care in cancer. Key advantages of this model lie in its simplicity and flexibility. While other approaches to modelling such as decision analysis may be more precise, they are also necessarily more complex and resource intensive to undertake [16]. The power of this simple filter model lies in the ability of the model to cope with uncertainty in the input data, to incorporate new research data as it emerges, and to ensure a logical pathway is followed when making decisions about health and medical research and services. The filter model can be easily altered and re-run, allowing a range of assumptions to be modelled to account for variability in input data. The visibility of the key parameters in the model allow scrutiny and the ability to vary these parameters to cope with uncertainty in the input. The model is highly flexible, and could potentially be tailored for use in other settings outside of depression in oncology, including to other outcomes, populations, and interventions. The model also highlights the data needed to make informed 
decisions on resource allocation and therefore helps to identify gaps in the available data.

\section{Limitations of the model}

The filter model is a simplified tool for guiding the allocation of resources in depression care, and therefore has a number of limitations. The central limitation is that the filter model represents only one of multiple pathways, and does not include indirect or unwanted costs, such as those associated with undetected and untreated depression or the cost of 'false positives'. Therefore the cost outcomes of the model need to be considered as direct system costs associated with implementing a change from baseline, rather than as overall healthcare system costs. The benefits of any improvement in depression care processes are also likely to be larger than suggested by the model, as broader downstream costs associated with untreated depression will be avoided by any improvement in detection and treatment. These could include, for example, avoided hospitalisations and emergency department visits. These downstream costs are not reflected in the model.

The model also assumes that each filter operates independently, whereas in reality there may be some overlap or interaction between filters. For example, a change in the way that providers respond to the detection of depression (filter 2), or in the type and effectiveness of treatment offered (filter 4), may impact on patient acceptance of the treatment (filter 3). Empirical testing will help to determine whether the static filter approach is an adequate representation of real-world systemic interactions.

Finally, some of the intervention costs may also be better described as costs per provider or per treatment centre, rather than as per patient, as required by the model. For example, costs for an intervention such as electronic screening for depression and provision of provider and patient feedback, could apply across filters and across centres, rather than per patient. In addition, the model assumes that costs are consistent across all patients. In practice there may be some variation in treatment costs, if for example, treatment type or intensity varies according to the patient's needs or preferences.

\section{Conclusion}

While this simple theoretical filter model needs empirical testing to confirm its functionality (or alternatively to refine and improve the model), it provides a tool to assist decision and policy makers to make transparent decisions about how to best allocate resources to improve depression outcomes in cancer care. These decisions are often made with little or no consideration of the available research evidence [14]. Despite its limitations, the filter model presents an opportunity to improve on current practice by ensuring a logical approach is applied to decision making and that this approach prompts users to consider: i) the relevant available evidence; and ii) the missing evidence that is necessary to make an informed decision. As a consequence of the latter point, the model contributes to identifying gaps in evidence which require more rigorous intervention work to provide reliable data about effectiveness and cost. The authors invite organisations and researchers to implement and test the model and provide suggestions for improvement. A copy of the model is available from the authors on request.

\section{Acknowledgments \\ n/a. \\ Funding \\ This work was supported by a Strategic Research Partnership Grant from the Cancer Council NSW to the Newcastle Cancer Control Collaborative. Infrastructure support was provided by the Hunter Medical Research Institute. Dr. Jamie Bryant is supported by an Australian Research Council Post-Doctoral Industry Fellowship. These funding bodies played no role in the design of this study, in interpretation of study data, or in the writing or publishing of this manuscript.}

Availability of data and materials

A copy of the filter model can be obtained from the corresponding author on request.

\section{Authors' contributions}

RSF, JB and RS were responsible for conceptualising the filter model. AS, SD and $\mathrm{CO}$ developed and tested the model. RS and NN tested and revised the model. All authors contributed to writing the manuscript. All authors have read and approved the final manuscript.

Ethics approval and consent to participate

This research paper did not involve any human or animal participants and therefore ethical approval was not sought for the study.

Consent for publication

Not applicable.

\section{Competing interests}

The authors declare that they have no competing interest.

\section{Publisher's Note}

Springer Nature remains neutral with regard to jurisdictional claims in published maps and institutional affiliations.

\section{Author details \\ ${ }^{1}$ Priority Research Centre for Health Behaviour, University of Newcastle, Callaghan, NSW, Australia. ${ }^{2}$ School of Medicine and Public Health, Faculty of Health and Medicine, University of Newcastle, Callaghan, NSW, Australia. ${ }^{3}$ Hunter Medical Research Institute, New Lambton Heights, NSW, Australia. ${ }^{4}$ Centre for Clinical Epidemiology and Biostatistics, University of Newcastle, Callaghan, NSW, Australia.}

Received: 20 December 2016 Accepted: 18 January 2018

Published online: 06 February 2018

References

1. Rodin G, Katz M, Lloyd N, Green E, Mackay J, Wong R. Treatment of depression in cancer patients. Curr Oncol. 2007;14(5):180.

2. Hopko DR, Bell JL, Armento M, Robertson S, Mullane C, Wolf N, Lejuez CW. Cognitive-behavior therapy for depressed cancer patients in a medical care setting. Behav Ther. 2008;39(2):126-36.

3. Rosenstein DL. Depression and end-of-life care for patients with cancer. Dialogues Clin Neurosci. 2011;13(1):101.

4. Fallowfield L, Ratcliffe $D$, Jenkins $V$, Saul J. Psychiatric morbidity and its recognition by doctors in patients with cancer. Br J Cancer. 2001;84(8):1011. 
5. Passik S, Dugan W, McDonald M, Rosenfeld B, Theobald D, Edgerton S Oncologists' recognition of depression in their patients with cancer. J Clin Oncol 1998, 16(4):1594-1600.

6. Weinberger MI, Bruce ML, Roth AJ, Breitbart W, Nelson CJ. Depression and barriers to mental health care in older cancer patients. Int. J. Geriatr. Psychiatry. 2011;26(1):21-6.

7. Carlson LE, Groff SL, Maciejewski O, Bultz BD. Screening for distress in lung and breast cancer outpatients: a randomized controlled trial. J Clin Oncol. 2010;28(33):4884-91.

8. Holland JC. Distress screening and the integration of psychosocial care into routine oncologic care. J Natl Compr Cancer Netw. 2013;11(5S):687-9.

9. Walker J, Sawhney A, Hansen CH, Ahmed S, Martin P, Symeonides S, Murray G, Sharpe M. Treatment of depression in adults with cancer: a systematic review of randomized controlled trials. Psychol Med. 2014;44(5):897-907.

10. Fann JR, Thomas-Rich AM, Katon WJ, Cowley D, Pepping M, BA MG, Gralow J. Major depression after breast cancer: a review of epidemiology and treatment. Gen Hosp Psychiatry. 2008:30(2):112-26.

11. Mitchell AJ, Vahabzadeh A, Magruder K. Screening for distress and depression in cancer settings: 10 lessons from 40 years of primary-care research. Psycho-Oncology. 2011;20(6):572-84.

12. Greenberg DB. Barriers to the treatment of depression in cancer patients. JNCI Monographs. 2004;2004(32):127-35.

13. Mitchell AJ. Screening for cancer-related distress: when is implementation successful and when is it unsuccessful? Acta Oncol. 2013;52(2):216-24.

14. Black N, Donald A. Evidence based policy: proceed with care. BMJ. 2001; 323(7307):275-9

15. Orton L, Lloyd-Williams F, Taylor-Robinson D, O'Flaherty M, Capewell S. The use of research evidence in public health decision making processes: systematic review. PLoS One. 2011;6(7):1-10.

16. Siebert $U$. When should decision-analytic modeling be used in the economic evaluation of health care? HEPAC. 2003;4(3):143-50.

17. Sun X, Faunce T. Decision-analytical Modelling in health-care economic evaluations. Eur J Health Econ. 2008;9(4):313-23.

18. Chilcott J, Tappenden P, Rawdin A, Johnson M, Kaltenthaler E, Paisley S, Papaioannou D, Shippam A. Avoiding and identifying errors in health technology assessment models: qualitative study and methodological review. Health Technol Assess. 2010;14(25):iii-v.

19. Rautenberg T, Hulme C, Edlin R. Methods to construct a step-by-step beginner's guide to decision analytic cost-effectiveness modeling. ClinicoEcon Outcomes Res: CEOR. 2016:8:573.

20. Mitchell AJ, Kaar S, Coggan C, Herdman J. Acceptability of common screening methods used to detect distress and related mood disorders - preferences of cancer specialists and non-specialists. PsychoOncology. 2008;17(3):226-36.

21. Burton MV, Parker RW, Farrell A, Bailey D, Conneely J, Booth S, Elcombe S. A randomized controlled trial of preoperative psychological preparation for mastectomy. Psycho-Oncology. 1995;4(1):1-19.

22. Newell S, Sanson-Fisher RW, Girgis A, Bonaventura A. How well do medical oncologists' perceptions reflect their patients' reported physical and psychosocial problems? Cancer. 1998;83(8):1640-51.

23. Mitchell AJ, Meader N, Davies E, Clover K, Carter GL, Loscalzo MJ, Linden W, Grassi L, Johansen C, Carlson LE. Meta-analysis of screening and case finding tools for depression in cancer: evidence based recommendations for clinical practice on behalf of the depression in cancer care consensus group. J Affect Disord. 2012;140(2):149-60.

24. Williams S, Dale J. The effectiveness of treatment for depression/depressive symptoms in adults with cancer: a systematic review. Br J Cancer. 2006; 94(3):372-90.

25. Yeh ML, Chung YC, MYF H, Hsu CC. Quantifying psychological distress among cancer patients in interventions and scales: a systematic review. Curr Pain Headache Rep. 2014;18(3):1-9.

26. Ell K, Quon B, Quinn DI, Dwight-Johnson M, Wells A, Lee P-J, Xie B. Improving treatment of depression among low-income patients with cancer: the design of the ADAPt-C study. Gen Hosp Psychiatry. 2007; 29(3):223-31.

27. Sharpe M, Strong V, Allen K, Rush R, Maguire P, House A, Ramirez A, Cull A Management of major depression in outpatients attending a cancer centre: a preliminary evaluation of a multicomponent cancer nurse-delivered intervention. Br J Cancer. 2004;90(2):310-3.

28. Sharpe M, Walker J, Hansen CH, Martin P, Symeonides S, Gourley C, Wall L, Weller D, Murray G. Integrated collaborative care for comorbid major depression in patients with cancer (SMaRT Oncology-2): a multicentre randomised controlled effectiveness trial. Lancet. 2014; 384(9948):1099-108

29. Walker J, Sharpe M. Depression care for people with cancer: a collaborative care intervention. Gen Hosp Psychiatry. 2009;31(5):436-41.

30. Carlson LE, Bultz BD. Cancer distress screening: needs, models, and methods. J Psychosom Res. 2003;55(5):403-9.

31. Pascoe S, Edelman S, Kidman A. Prevalence of psychological distress and use of support services by cancer patients at Sydney hospitals. Aust N Z J Psychiatry. 2000;34(5):785-91.

32. Walker J, Hansen CH, Martin P, Symeonides S, Ramessur R, Murray G, Sharpe M. Prevalence, associations, and adequacy of treatment of major depression in patients with cancer: a cross-sectional analysis of routinely collected clinical data. Lancet Psychiatry. 2014;1(5):343-50.

33. Baker-Glenn EA, Park B, Granger L, Symonds P, Mitchell AJ. Desire for psychological support in cancer patients with depression or distress: validation of a simple help question. Psycho-Oncology. 2011;20(5):525-31.

34. Graves KD, Arnold SM, Love CL, Kirsh KL, Moore PG, Passik SD: Distress screening in a multidisciplinary lung cancer clinic: prevalence and predictors of clinically significant distress. Lung Cancer 2007, 55(2):215-24.

35. Clover KA, Mitchell AJ, Britton B, Carter G: Why do oncology outpatients who report emotional distress decline help? Psycho-Oncology. 2014;24(7): $812-18$

36. Bidstrup PE, Johansen C, Mitchell AJ. Screening for cancer-related distress: summary of evidence from tools to programmes. Acta Oncol. 2011;50(2): 194-204.

37. Carlson LE, Waller A, Mitchell AJ. Screening for distress and unmet needs in patients with cancer: review and recommendations. J Clin Oncol. 2012; 30(11):1160-77.

38. Akechi T, Okuyama T, Onishi J, Morita T, Furukawa TA. Psychotherapy for depression among incurable cancer patients. Cochrane Libr. 2008. Issue 2. Art. No.: CD005537. https://doi.org/10.1002/14651858.CD005537.pub2.

39. Rodin G, Lloyd N, Katz M, Green E, Mackay JA, Wong RK. Care SCGGoCCOPiE-B: the treatment of depression in cancer patients: a systematic review. Support Care Cancer. 2007;15(2):123-36.

\section{Submit your next manuscript to BioMed Central and we will help you at every step:}

- We accept pre-submission inquiries

- Our selector tool helps you to find the most relevant journal

- We provide round the clock customer support

- Convenient online submission

- Thorough peer review

- Inclusion in PubMed and all major indexing services

- Maximum visibility for your research

Submit your manuscript at www.biomedcentral.com/submit
) Biomed Central 